\title{
Manganese Oxide on Carbon Fabric for Flexible Supercapacitors
}

\author{
Jianfeng Zhang, ${ }^{1}$ Mujun Chen, ${ }^{1}$ Yunwang Ge, ${ }^{2}$ and Qi Liu ${ }^{2}$ \\ ${ }^{1}$ College of Information Engineering, Henan Vocational College of Agriculture, Zhengzhou 451450, China \\ ${ }^{2}$ College of Electrical Engineering and Automation, Luoyang Institute of Science and Technology, Luoyang 471023, China
}

Correspondence should be addressed to Qi Liu; liuqi8349@163.com

Received 5 May 2016; Accepted 26 May 2016

Academic Editor: Yang Song

Copyright (C) 2016 Jianfeng Zhang et al. This is an open access article distributed under the Creative Commons Attribution License, which permits unrestricted use, distribution, and reproduction in any medium, provided the original work is properly cited.

\begin{abstract}
We report the fabrication of uniform large-area manganese oxide $\left(\mathrm{MnO}_{2}\right)$ nanosheets on carbon fabric which oxidized using $\mathrm{O}_{2}$ plasma treatment $\left(\mathrm{MnO}_{2} / \mathrm{O}_{2}\right.$-carbon fabric) via electrodeposition process and their implementation as supercapacitor electrodes. Electrochemical measurements demonstrated that $\mathrm{MnO}_{2} / \mathrm{O}_{2}$-carbon fabric exhibited capacitance as high as $275 \mathrm{~F} / \mathrm{g}$ at a scan rate of $5 \mathrm{mV} / \mathrm{s}$; in addition, it showed an excellent cycling performance (less than 20\% capacitance loss after 10,000 cycles). All the results suggest that $\mathrm{MnO}_{2} / \mathrm{O}_{2}$-carbon fabric is a promising electrode material which has great potential for application on flexible supercapacitors.
\end{abstract}

\section{Introduction}

With the rapid development of economy, the global energy consumption has been increasing for decades. As a result, the traditional fossil energy faces serious shortages. Green renewable energy such as solar cells and wind power generation set is desired. However, most of the new energy sources are intermittent and unsustainable, which hinder their application greatly $[1,2]$. The energy supply gap deriving from the discontinuous characteristics of the renewable sources can be filled by coupling them with energy storage devices, such as supercapacitors (SCs) and batteries, which are able to store energy and deliver it to power the electronics [3-5].

SCs have drawn great attention in addressing the emerging energy demands due to the advantages of high power density, fast charge/discharge rates, and long cycle life [6-8]. Generally, SCs could be categorized into two types according to the charge storage mechanisms: electrochemical double layer capacitors (EDLCs) $[9,10]$ and pseudocapacitors (PSCs) [11-13]. EDLCs attract charges on the electrode-electrolyte interface of electrode materials electrostatically; meanwhile PSCs store energy via fast redox reaction on/near electrode surface $[5,14,15]$. Each of the two types of SCs has advantages and disadvantages, respectively. EDLCs use carbon materials such as carbon nanotubes (CNTs), graphene, carbon nanofibers (CFs), and carbon onion as electrode materials, while PSCs employ transition metal oxides or conducting polymers such as manganese oxide $\left(\mathrm{MnO}_{2}\right)$, molybdenum trioxide $\left(\mathrm{MoO}_{3}\right)$, and polyaniline as electrode materials. Carbon materials usually hold higher physical and chemical stability, better electrical conductivity, and higher specific surface than those materials for PSCs, resulting in higher rate capability and longer durability than the latter. However, the theoretical capacitance of carbon materials is much lower than that for transition metal oxides, leading to the fact that most specific capacitance of carbon-based EDLCs are less than $150 \mathrm{~F} / \mathrm{g}[3,16-18]$. On the contrary, PSCs exhibit higher capacitance and energy density through Faradic reaction, but suffered by the poor electrical conductivity $[12,19]$. In this regard, if we can combine both the advantages of the two types of SCs and solve the shortcomings, then the SCs with enhanced electrochemical properties could be expected.

$\mathrm{MnO}_{2}$ is one of the most attractive pseudocapacitive materials for the superior theoretical capacitance $(1370 \mathrm{~F} / \mathrm{g})$, low cost, and abundance. Nevertheless, it suffered from the poor electric conductivity $\left(10^{-5}-10^{-6} \mathrm{~S} / \mathrm{cm}\right)$, leading to the fact that the practice capacitance is much lower than the theoretical value [20,21]. Growth of pseudocapacitive materials on well conductive carbon substrates not only can facilitate the diffusion of electrolyte ions but also can improve the transport of electrons, thus enhancing the electrochemical 


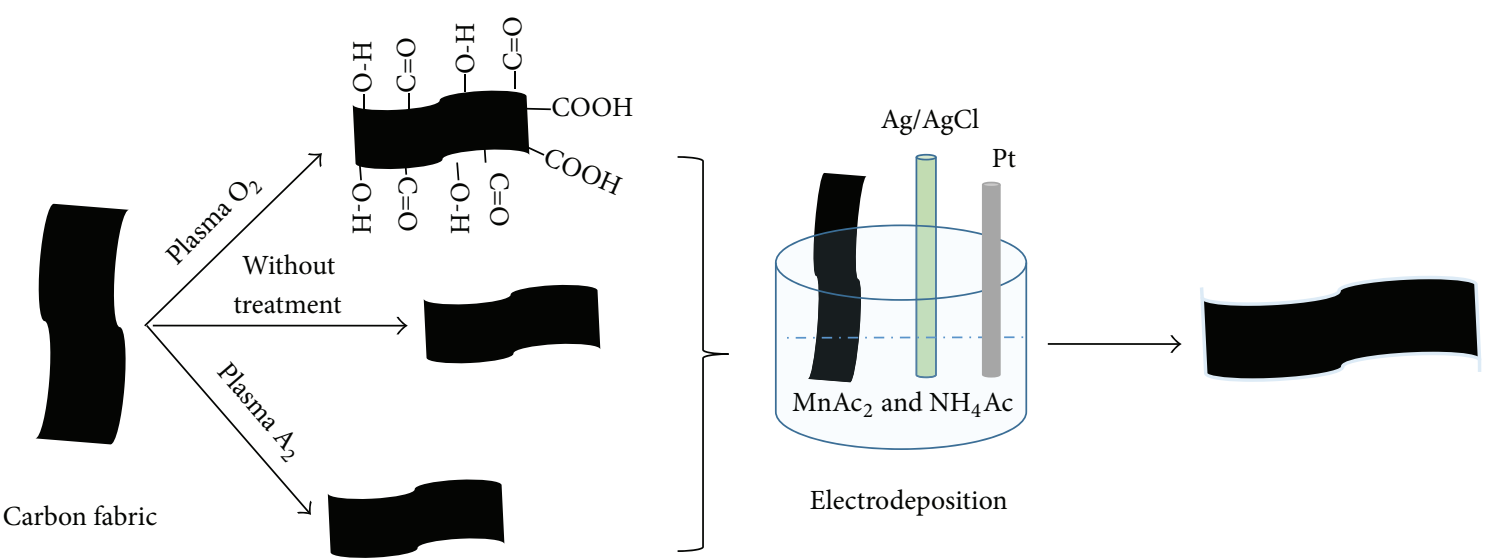

FIGURE 1: Schematic of the fabrication procedure for $\mathrm{MnO}_{2}$-carbon composites.

properties [22, 23]. Furthermore, the hybrid structures may broaden their applications in energy storage device [24].

Herein, different surface treatments were employed to carbon fabric for assessing the influence of different treatments on the surface chemical states. We choose carbon fabric as substrates here for its low cost, good electrical conductivity, excellent chemical stability, and the flexible nature. Characterizations showed that the oxidic carbon fabric substrate is more suitable for electrodeposition of $\mathrm{MnO}_{2}$, for the reason of more oxygen containing functional groups which can act as nucleation points of $\mathrm{MnO}_{2}$. As a result, it exhibits a high specific capacitance $(275 \mathrm{~F} / \mathrm{g})$ at a current density of $5 \mathrm{mV} / \mathrm{s}$. In addition, the oxidic carbon fabric- $\mathrm{MnO}_{2}$ showed excellent long-term cycle stability.

\section{Experimental}

2.1. Synthesis of $\mathrm{MnO}_{2} /$ Carbon Fabric. The carbon fabric was oxidized or reduced using plasma technology. Firstly, carbon fabric was cut into the same size $\left(0.9 \times 1.8 \mathrm{~cm}^{2}\right)$. Then it was cleaned ultrasonically for $15 \mathrm{~min}$ by acetone, ethanol, and deionized water, respectively. After drying at $70^{\circ} \mathrm{C}$, the carbon fabric was placed in plasma sample chamber for oxidation or reduction treatments. The treated carbon fabric was ready for next experiments.

A template-free electrodeposition method was introduced to fabricate $\mathrm{MnO}_{2}$ /carbon fabric in a three-electrode cell. Carbon fabric, a graphite rod, and a saturated $\mathrm{Ag} / \mathrm{AgCl}$ electrode were used as working electrode, counter electrode, and reference electrode, respectively. The solution containing $0.01 \mathrm{M}$ manganese acetate $\left(\mathrm{MnAc}_{2}\right)$ and $0.02 \mathrm{M}$ ammonium acetate $\left(\mathrm{NH}_{4} \mathrm{Ac}\right)$ was used as electrolyte. The constant current and deposition time are $0.1 \mathrm{~mA} / \mathrm{cm}^{2}$ and $30 \mathrm{~min}$, respectively.

2.2. Fabrication of SCs Electrodes. One piece of $\mathrm{MnO}_{2} /$ carbon fabric was used as working electrode. The saturated $\mathrm{Ag} / \mathrm{AgCl}$ electrode, a piece of pure $\mathrm{Pt}$ foil, and $1 \mathrm{M}$ sodium sulfate $\left(\mathrm{Na}_{2} \mathrm{SO}_{4}\right)$ aqueous solution were employed as reference electrode, counter electrode, and electrolyte, respectively.
2.3. Characterization. The morphology of $\mathrm{MnO}_{2}$ /carbon fabric was analyzed using scanning electron microscopy (SEM, JSM-7100F). The transmission electron microscopy (TEM) and high-resolution transmission electron microscopy (HRTEM) were performed on a JEOL-2010 HR transmission electron microscope to further investigate the internal structures and lattice fringes. The crystal structure of $\mathrm{MnO}_{2} /$ carbon fabric was characterized by X-ray diffraction using the $\mathrm{Cu} \mathrm{K}$ radiation $(\lambda=1.5418 \AA$ ) (XRD, D8-Advanced Bruker-AXS).

The electrochemical workstation (Chenhua, CHI 660D) was used to perform cyclic voltammetry (CV) and chronopotentiometry measurements. Autolab (PGSTAT302N) was used to measure the electrochemical impedance spectroscopy (EIS) with potential amplitude of $10 \mathrm{mV}$ under the frequency ranging from $10 \mathrm{kHz}$ to $100 \mathrm{mHz}$.

\section{Results and Discussion}

The fabrication procedure for the $\mathrm{MnO}_{2}$-carbon fabric composites is illustrated in Figure 1. Firstly, the carbon fabric cut in $0.9 \times 1.8 \mathrm{~cm}^{2}$ is washed by deionized water, acetone, and ethanol, respectively. After drying, the carbon fabric was reduced or oxidized by plasma to add redox active functional groups on carbon fabric. Finally, the efficient electrodeposition method was adopted to prepare $\mathrm{MnO}_{2}$ carbon fabric composites.

The morphology of the original carbon fabric and asprepared $\mathrm{MnO}_{2}$ /carbon fabric samples was characterized by SEM, as shown in Figure 2. Figure 2(a) clearly shows that there is no other substance on the carbon fiber surface except very small amount of impurities. After electrodeposition, all the carbon fibers were covered by a multitude of $\mathrm{MnO}_{2}$ on their surface (Figures 2(b)-2(d)). However, from Figures 2(b) and 2(c), it can be observed clearly that both the electrodeposition samples based on the pristine carbon fabric $\left(\mathrm{MnO}_{2} /\right.$ carbon fabric) and the carbon fabric reduced under Ar atmosphere $\left(\mathrm{MnO}_{2} / \mathrm{Ar}\right.$-carbon fabric) covered by many flower-like $\mathrm{MnO}_{2}$ on the surface which exhibit uneven surface characteristics, suggesting lower pseudocapacitive electrochemical performance. Meanwhile, there is lots of sheet 


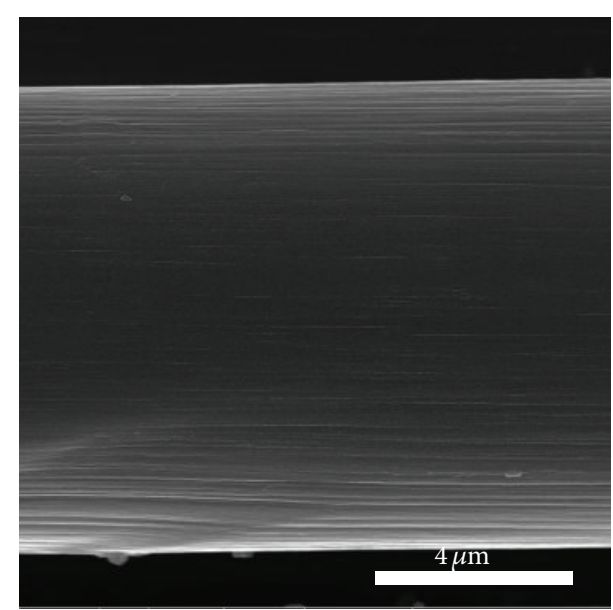

(a)

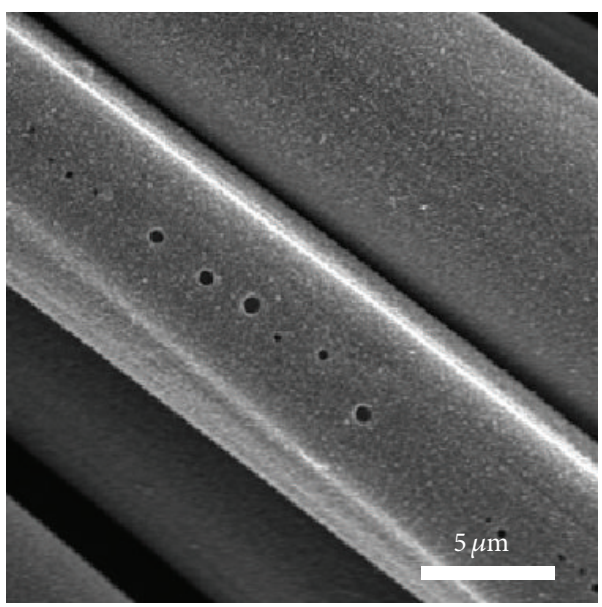

(c)

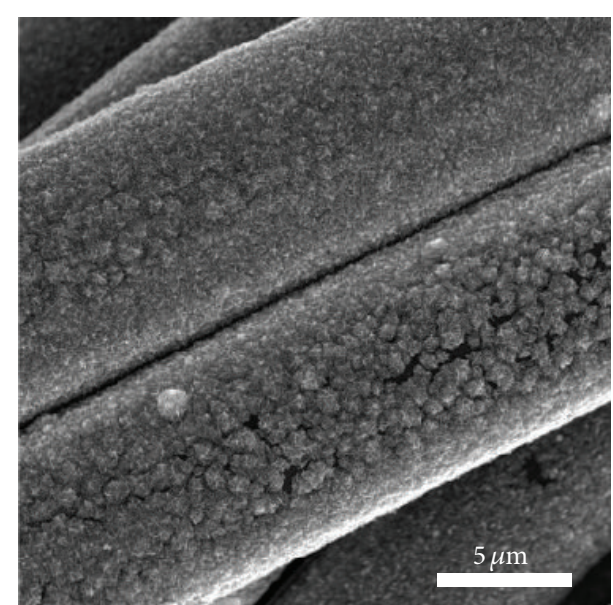

(b)

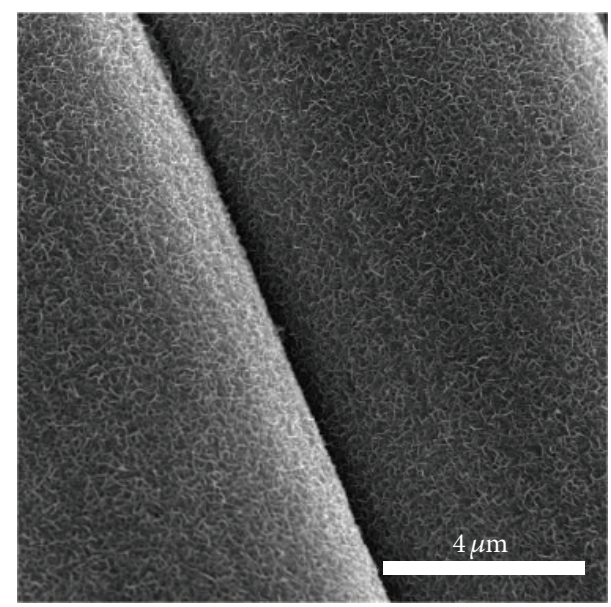

(d)

Figure 2: The SEM images of (a) the rare carbon fabric, (b) $\mathrm{MnO}_{2} /$ carbon fabric, (c) $\mathrm{MnO}_{2} / \mathrm{Ar}_{2}$-carbon fabric, and (d) $\mathrm{MnO}_{2} / \mathrm{O}_{2}$-carbon fabric.

$\mathrm{MnO}_{2}$ covering densely the carbon fabric fiber surface which oxidized under $\mathrm{O}_{2}$ atmosphere $\left(\mathrm{MnO}_{2} / \mathrm{O}_{2}\right.$-carbon fabric). The uniform surface morphology implies that it may have good electrochemical performance. Hence, we will further investigate the internal structure and electrochemical properties of $\mathrm{MnO}_{2} / \mathrm{O}_{2}$-carbon fabric.

TEM was introduced to further investigate the morphology of $\mathrm{MnO}_{2} / \mathrm{O}_{2}$-carbon fabric, as shown in Figure 3. According to the low resolution TEM image (Figure 3(a)), the electrodeposited $\mathrm{MnO}_{2}$ is a sheet shape with a nanoscale thickness. HRTEM image (Figure 3(b)) shows the interplanar spacings for the two perpendicular directions to be $\sim 0.48 \mathrm{~nm}$. This value corresponds to $d_{101}$ of the tetragonal $\mathrm{MnO}_{2}$ phase (JCPDS reference card number 18-0802).

XRD pattern was collected from the electrodeposited products for investigating the crystal phase, as shown in Figure 4 . From the spectrum, there are six peaks located at $2 \theta$ $=11.4^{\circ}, 21.4^{\circ}, 36.5^{\circ}, 37.7^{\circ}, 41.3^{\circ}, 54.9^{\circ}$, and $65.7^{\circ}$. Among them, the broad peak located at $21.4^{\circ}$ not only corresponds to the amorphous carbon but also can be assigned to the reflection of (101) of tetragonal $\mathrm{MnO}_{2}$. Meanwhile, the other five peaks can be well assigned to the tetragonal $\mathrm{MnO}_{2}$ (JCPDS reference card number 18-0802), which is consistent well with the TEM observations. Hence, the products synthesized by electrodeposition procedure are tetragonal $\mathrm{MnO}_{2}$.

To study the electrochemical performances of $\mathrm{MnO}_{2} / \mathrm{O}_{2}$ carbon fabric, cyclic voltammetry $(\mathrm{CV})$ and galvanostatic charge-discharge (GCD) were conducted using a threeelectrode configuration with $\mathrm{Ag} / \mathrm{AgCl}$ as reference electrode and $1 \mathrm{M} \mathrm{Na}_{2} \mathrm{SO}_{4}$ as electrolyte. The typical $\mathrm{CV}$ curves of $\mathrm{MnO}_{2} / \mathrm{O}_{2}$-carbon fabric are displayed in Figure 5(a) with scan rates from $5 \mathrm{mV} / \mathrm{s}$ to $100 \mathrm{mV} / \mathrm{s}$. From the curves, even the scan rate has been increased to $100 \mathrm{mV} / \mathrm{s}$; the $\mathrm{CV}$ curves retain a symmetrical rectangular shape, which demonstrate that the $\mathrm{MnO}_{2} / \mathrm{O}_{2}$-carbon fabric not only holds rapid capacitive response but also has good electronic conductivity. In addition, the GCD curves of $\mathrm{MnO}_{2} / \mathrm{O}_{2}$-carbon fabric collected at various current densities (Figure 5(b)) remain of semisymmetric shape revealing reversible ion adsorption/reaction on the surface and good Coulombic efficiency. Moreover, the 


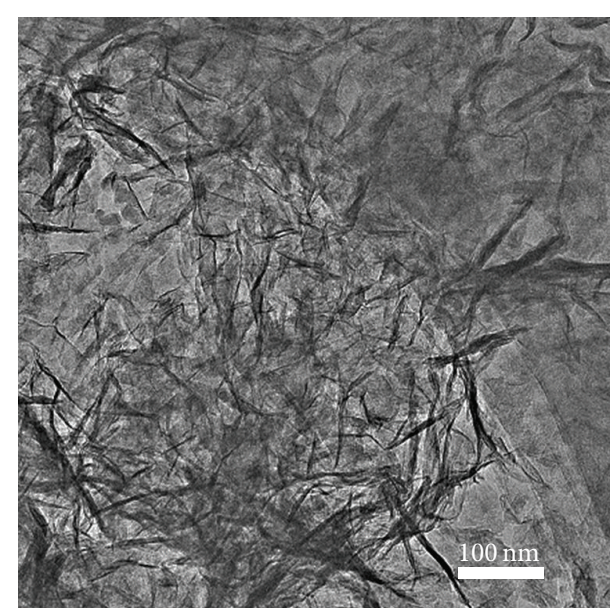

(a)

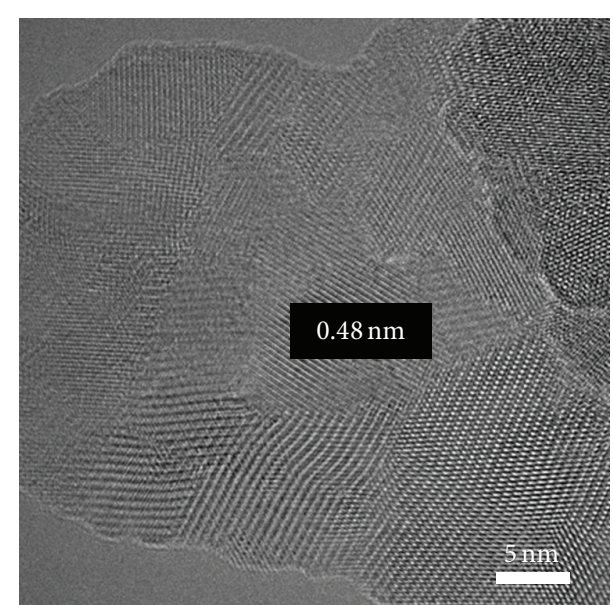

(b)

Figure 3: (a) TEM image and (b) HRTEM image of $\mathrm{MnO}_{2} / \mathrm{O}_{2}$-carbon fabric.

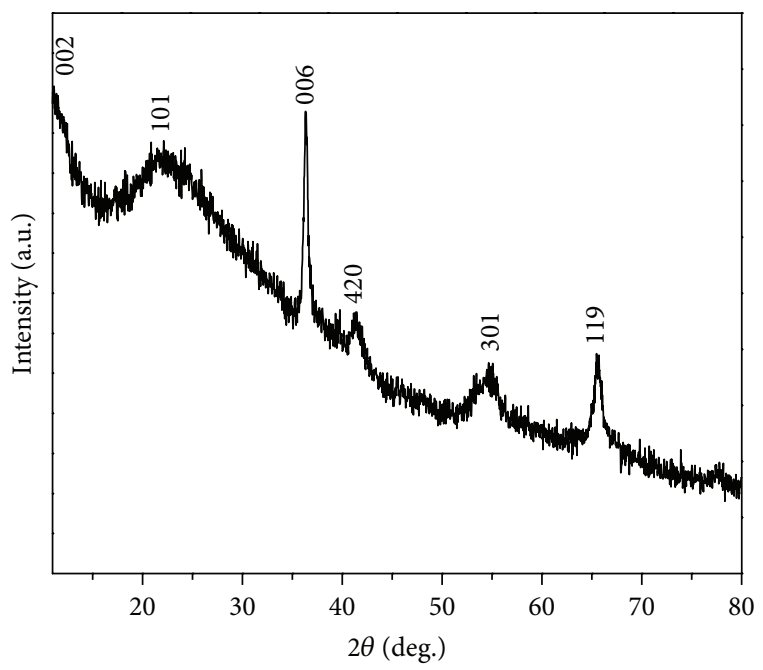

FIGURE 4: The XRD pattern of the electrodeposited products.

IR drop derived from the GCD curves of $\mathrm{MnO}_{2} / \mathrm{O}_{2}$-carbon fabric is as low as $0.05 \mathrm{~V}$ at $2 \mathrm{~A} / \mathrm{g}$, suggesting the $\mathrm{MnO}_{2} / \mathrm{O}_{2}$ carbon fabric has good electrical conductivity. Combined with the excellent electrical conductivity of the carbon fabric and high theory capacitance value of manganese $\mathrm{MnO}_{2}$, enhanced properties are expected.

The specific capacitance derived from the discharge curves measured at different current densities could be calculated according to the following equation [1]:

$$
C_{s}=\frac{Q}{\Delta U \times m},
$$

where $C_{s}$ is the mass specific capacitance of the $\mathrm{MnO}_{2} / \mathrm{O}_{2}$ carbon fabric, $Q$ is the average electric quantity, $\Delta U$ is the working voltage window of the active material, and $m$ is the mass of the active material.

The specific capacitance of the $\mathrm{MnO}_{2} / \mathrm{O}_{2}$-carbon fabric calculated from their $\mathrm{CV}$ curves with different scan rates was summarized in Figure 5(c). From the specific capacitance change curve, the specific capacitance value decreases along with the increase of the scan rate. The highest specific capacitance for $\mathrm{MnO}_{2} / \mathrm{O}_{2}$-carbon fabric can achieve $275 \mathrm{~F} / \mathrm{g}$ at the scan rate of $5 \mathrm{mV} / \mathrm{s}$. This value is higher than those recently reported for other $\mathrm{MnO}_{2}$ electrodes [25-27]. The specific capacitance of $\mathrm{MnO}_{2} / \mathrm{O}_{2}$-carbon fabric still remains more than $45 \%(120 \mathrm{~F} / \mathrm{g})$ comparable with that obtained at $5 \mathrm{mV} / \mathrm{s}$ when the scan rate increases to $200 \mathrm{mV} / \mathrm{s}$. It is important to note that the specific capacitance contribution of the carbon fabric is rather small $[28,29]$. Thus, the $\mathrm{MnO}_{2} / \mathrm{O}_{2}$-carbon fabric has high rate capability which provides a benefit for the potential applications. The high rate capability could be attributed to the unique free-standing composite structure including good-electrical-conductivity carbon fibers and disordered nanosheets which not only makes electron transportation and ion diffusion convenient, but also facilitates the reaction of active species, so that a good rate capability was obtained.

Beside high specific capacitance, good cycling performance is also one of the most important characteristics for high-performance supercapacitors [24]. In present work, GCD cycling at a current density of $5 \mathrm{~A} / \mathrm{g}$ was employed to evaluate the long-term stability of the $\mathrm{MnO}_{2} / \mathrm{O}_{2}$-carbon fabric electrode. From Figure 5(d), it is observed clearly that the specific capacitance for $\mathrm{MnO}_{2} / \mathrm{O}_{2}$-carbon fabric remains more than $70 \%$ of the initial capacitance over the first 5000 cycles. Meanwhile, the capacitance even slightly increases to about $80 \%$ of the initial capacitance after 10,000 cycles. The specific capacitance increase of the $\mathrm{MnO}_{2} / \mathrm{O}_{2}$-carbon fabric could be assigned to the following reasons: after the beginning circulations, the intercalation and deintercalation of the active species had been reacted completely, leading to the increase of active points; hence the specific capacitance was enhanced. This outstanding long-term stability performance could be attributed to the good contact between $\mathrm{MnO}_{2}$ nanosheets and carbon fibers. Furthermore, this cycling performance is higher than those recently reported results 


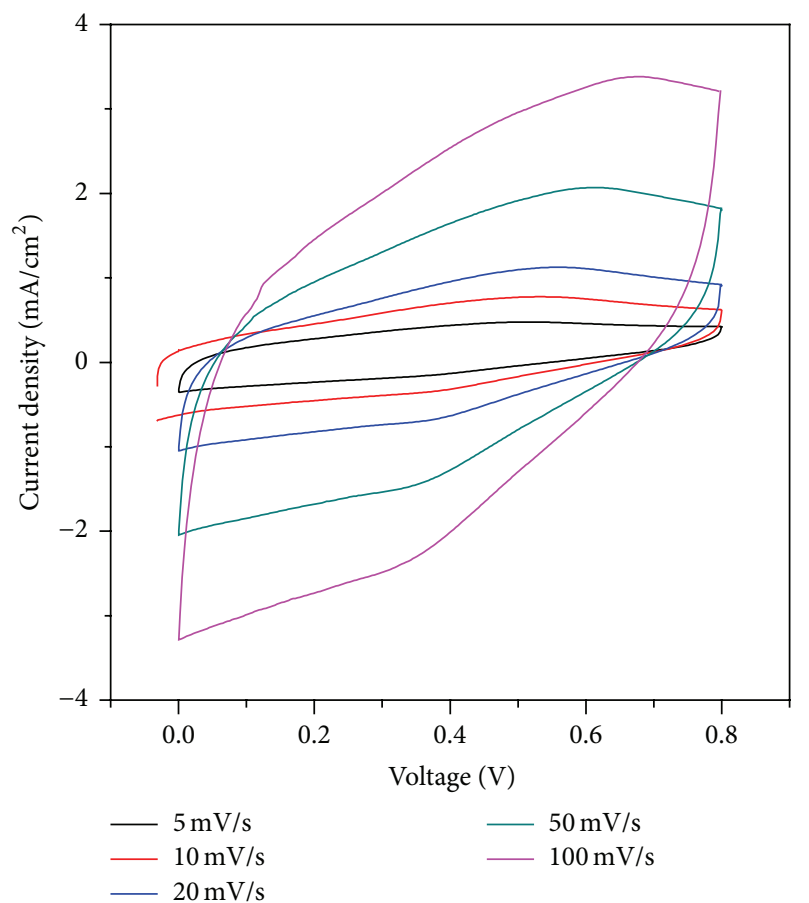

(a)

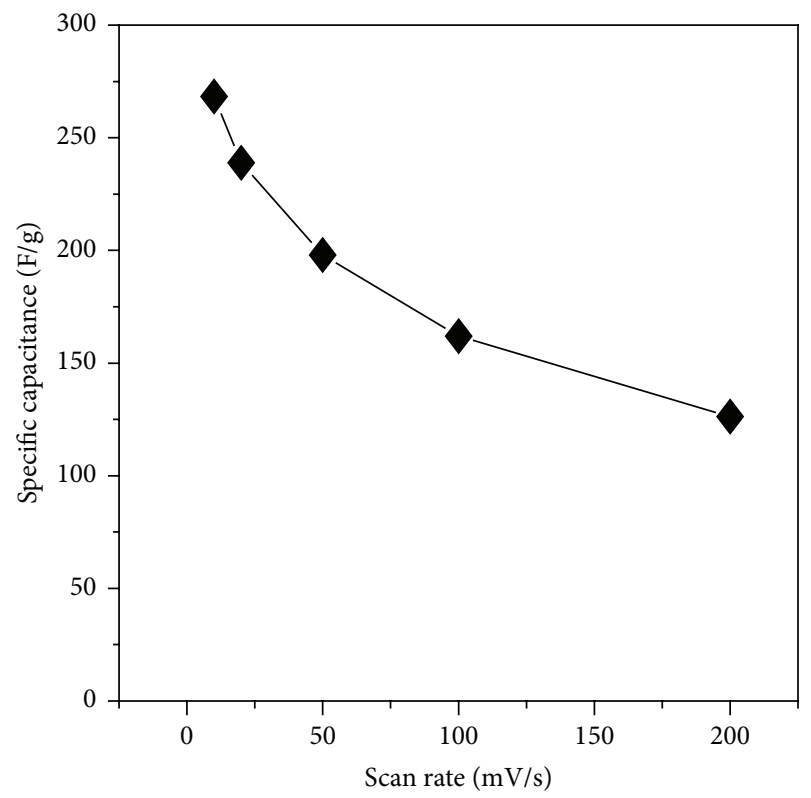

(c)

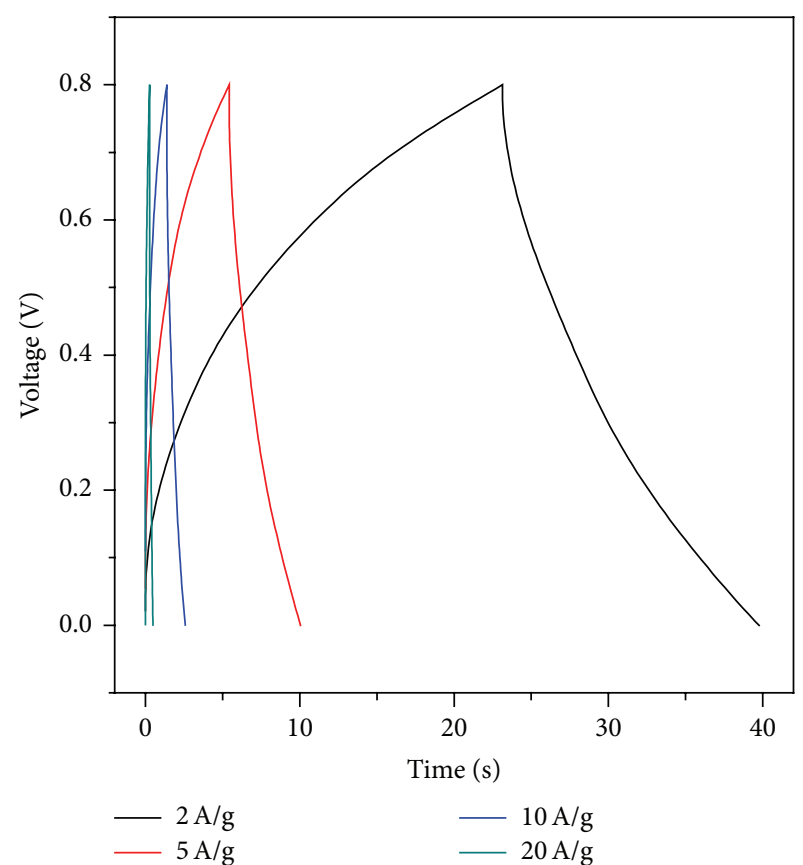

(b)

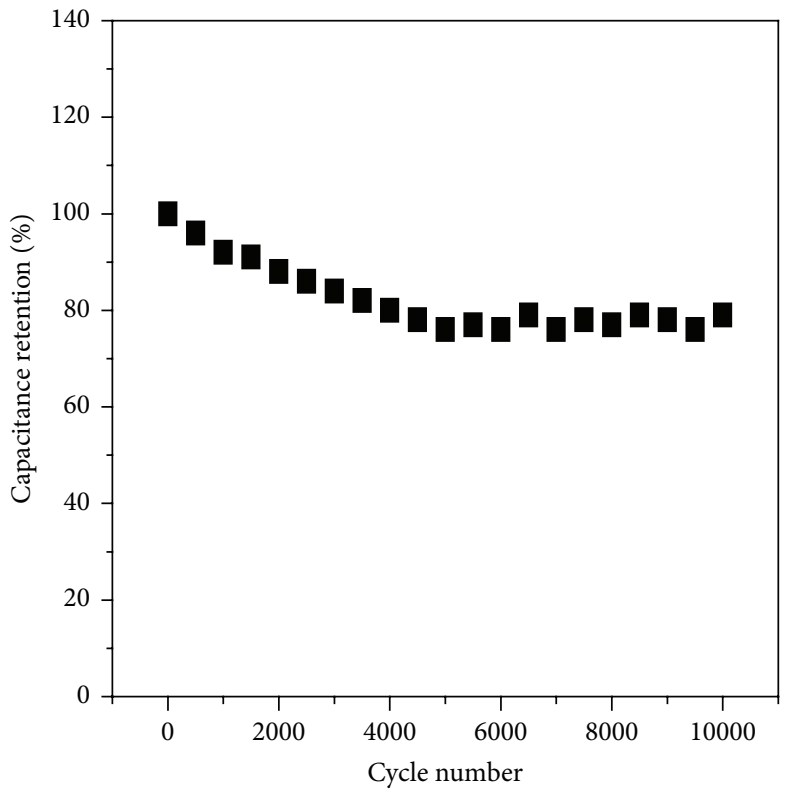

(d)

Figure 5: (a) Cyclic voltammogram curves, (b) galvanostatic charge-discharge curves, (c) specific capacitance, and (d) cyclic performance of $\mathrm{MnO}_{2} / \mathrm{O}_{2}$-carbon fabric, respectively.

for $\mathrm{MnO}_{2}$ nanotube arrays [30], $\mathrm{MnO}_{2}$ nanowires [31], and hierarchical tubular $\mathrm{MnO}_{2}$ structures [32].

\section{Conclusions}

In summary, uniform large-area $\mathrm{MnO}_{2}$ nanosheets were successfully fabricated on flexible carbon fabric through a simple electrodeposition method. The as-electrodeposited $\mathrm{MnO}_{2} /$ $\mathrm{O}_{2}$-carbon fabric was implemented as supercapacitor electrodes and shows outstanding electrochemical performance such as high specific capacitance and good cyclic stability. These results suggest that $\mathrm{MnO}_{2} / \mathrm{O}_{2}$-carbon fabric is a promising electrode material which has great potential for application in flexible supercapacitors. 


\section{Competing Interests}

The authors declare that they have no competing interests.

\section{Acknowledgments}

This work is supported by the Key Scientific Research Project of Higher Education of Henan Province (15B510012) and the Starting Fund for High-Scientific Study of Genius of Luoyang Institute of Science and Technology (2014BZ09).

\section{References}

[1] J. R. Miller and P. Simon, "Electrochemical capacitors for energy management," Science, vol. 321, no. 5889, pp. 651-652, 2008.

[2] M. F. El-Kady and R. B. Kaner, "Scalable fabrication of highpower graphene micro-supercapacitors for flexible and on-chip energy storage," Nature Communications, vol. 4, article 1475, 2013.

[3] P. Simon and Y. Gogotsi, "Materials for electrochemical capacitors," Nature Materials, vol. 7, no. 11, pp. 845-854, 2008.

[4] C. D. Lokhande, D. P. Dubal, and O.-S. Joo, "Metal oxide thin film based supercapacitors," Current Applied Physics, vol. 11, no. 3, pp. 255-270, 2011.

[5] W. F. Wei, X. W. Cui, W. X. Chen, and D. G. Ivey, "Manganese oxide-based materials as electrochemical supercapacitor electrodes," Chemical Society Reviews, vol. 40, no. 3, pp. 1697-1721, 2011.

[6] L. Hu and Y. Cui, "Energy and environmental nanotechnology in conductive paper and textiles," Energy and Environmental Science, vol. 5, no. 4, pp. 6423-6435, 2012.

[7] C. Yuan, H. B. Wu, Y. Xie, and X. W. Lou, "Mixed transitionmetal oxides: design, synthesis, and energy-related applications," Angewandte Chemie-International Edition, vol. 53, no. 6, pp. 1488-1504, 2014.

[8] X. Li and B. Wei, "Facile synthesis and super capacitive behavior of SWNT/ $\mathrm{MnO}_{2}$ hybrid films," Nano Energy, vol. 1, no. 3, pp. 479-487, 2012.

[9] Y. Qiu, X. Zhang, and S. Yang, "High performance supercapacitors based on highly conductive nitrogen-doped graphene sheets," Physical Chemistry Chemical Physics, vol. 13, no. 27, pp. 12554-12558, 2011.

[10] D. Sun, X. Yan, J. Lang, and Q. Xue, "High performance supercapacitor electrode based on graphene paper via flame-induced reduction of graphene oxide paper," Journal of Power Sources, vol. 222, pp. 52-58, 2013.

[11] L. Chen, L.-J. Sun, F. Luan, Y. Liang, Y. Li, and X.-X. Liu, "Synthesis and pseudocapacitive studies of composite films of polyaniline and manganese oxide nanoparticles," Journal of Power Sources, vol. 195, no. 11, pp. 3742-3747, 2010.

[12] S. L. Candelaria, B. B. Garcia, D. Liu, and G. Cao, "Nitrogen modification of highly porous carbon for improved supercapacitor performance," Journal of Materials Chemistry, vol. 22, no. 19, pp. 9884-9889, 2012.

[13] D. Yuan, J. Chen, J. Zeng, and S. Tan, "Preparation of monodisperse carbon nanospheres for electrochemical capacitors," Electrochemistry Communications, vol. 10, no. 7, pp. 1067-1070, 2008.

[14] P. Simon and Y. Gogotsi, "Capacitive energy storage in nanostructured carbon-electrolyte systems," Accounts of Chemical Research, vol. 46, no. 5, pp. 1094-1103, 2013.
[15] G. Zhao, N. Zhang, and K. Sun, "Porous $\mathrm{MoO}_{3}$ films with ultra-short relaxation time used for supercapacitors," Materials Research Bulletin, vol. 48, no. 3, pp. 1328-1332, 2013.

[16] N. Xiao, D. Lau, W. Shi et al., "A simple process to prepare nitrogen-modified few-layer graphene for a supercapacitor electrode," Carbon, vol. 57, pp. 184-190, 2013.

[17] Y. Gao, Y. S. Zhou, M. Qian et al., "Chemical activation of carbon nano-onions for high-rate supercapacitor electrodes," Carbon, vol. 51, no. 1, pp. 52-58, 2013.

[18] Y. P. Zhai, Y. Q. Dou, D. Y. Zhao, P. F. Fulvio, R. T. Mayes, and S. Dai, "Carbon materials for chemical capacitive energy storage," Advanced Materials, vol. 23, no. 42, pp. 4828-4850, 2011.

[19] R. B. Rakhi, W. Chen, D. Cha, and H. N. Alshareef, "Substrate dependent self-organization of mesoporous cobalt oxide nanowires with remarkable pseudocapacitance," Nano Letters, vol.12, no. 5, pp. 2559-2567, 2012.

[20] Y. B. He, G. R. Li, Z. L. Wang, C. Y. Su, and Y. X. Tong, "Singlecrystal $\mathrm{ZnO}$ nanorod/amorphous and nanoporous metal oxide shell composites: controllable electrochemical synthesis and enhanced supercapacitor performances," Energy \& Environmental Science, vol. 4, no. 4, pp. 1288-1292, 2011.

[21] M. Ghaemi, F. Ataherian, A. Zolfaghari, and S. M. Jafari, "Charge storage mechanism of sonochemically prepared $\mathrm{MnO} 2$ as supercapacitor electrode: Effects of physisorbed water and proton conduction," Electrochimica Acta, vol. 53, no. 14, pp. 4607-4614, 2008.

[22] S. Dong, X. Chen, L. Gu et al., "One dimensional $\mathrm{MnO}_{2}$ /titanium nitride nanotube coaxial arrays for high performance electrochemical capacitive energy storage," Energy \& Environmental Science, vol. 4, no. 9, pp. 3502-3508, 2011.

[23] L. Bao, J. Zang, and X. Li, "Flexible $\mathrm{Zn}_{2} \mathrm{SnO}_{4} / \mathrm{MnO}_{2}$ core/shell nanocable-carbon microfiber hybrid composites for highperformance supercapacitor electrodes," Nano Letters, vol. 11, no. 3, pp. 1215-1220, 2011.

[24] M. Yu, T. Zhai, X. Lu et al., "Manganese dioxide nanorod arrays on carbon fabric for flexible solid-state supercapacitors," Journal of Power Sources, vol. 239, pp. 64-71, 2013.

[25] P. Yu, X. Zhang, D. Wang, L. Wang, and Y. Ma, "Shape-controlled synthesis of 3D hierarchical $\mathrm{MnO}_{2}$ nanostructures for electrochemical supercapacitors," Crystal Growth and Design, vol. 9, no. 1, pp. 528-533, 2009.

[26] S. Devaraj and N. Munichandraiah, "Effect of crystallographic structure of $\mathrm{MnO}_{2}$ on its electrochemical capacitance properties," The Journal of Physical Chemistry C, vol. 112, no. 11, pp. 4406-4417, 2008.

[27] N. Nagarajan, M. Cheong, and I. Zhitomirsky, "Electrochemical capacitance of $\mathrm{MnO}_{x}$ films," Materials Chemistry and Physics, vol. 103, no. 1, pp. 47-53, 2007.

[28] T. Zhai, X. Lu, Y. Ling et al., "A new benchmark capacitance for supercapacitor anodes by mixed-valence sulfur-doped $\mathrm{V}_{6} \mathrm{O}_{13-\mathrm{x}}$, Advanced Materials, vol. 26, no. 33, pp. 5869-5875, 2014.

[29] X. Lu, M. Yu, G. Wang et al., "H-TiO $@ \mathrm{MnO}_{2} / / \mathrm{H}-\mathrm{TiO}_{2} @ \mathrm{C}$ core-shell nanowires for high performance and flexible asymmetric supercapacitors," Advanced Materials, vol. 25, no. 2, pp. 267-272, 2013.

[30] H. Xia, J. Feng, H. Wang, M. O. Lai, and L. $\mathrm{Lu}$, " $\mathrm{MnO}_{2}$ nanotube and nanowire arrays by electrochemical deposition for supercapacitors," Journal of Power Sources, vol. 195, no. 13, pp. 4410-4413, 2010. 
[31] S.-L. Chou, J.-Z. Wang, S.-Y. Chew, H.-K. Liu, and S.-X. Dou, "Electrodeposition of $\mathrm{MnO}_{2}$ nanowires on carbon nanotube paper as free-standing, flexible electrode for supercapacitors," Electrochemistry Communications, vol. 10, no. 11, pp. 1724-1727, 2008.

[32] H. Zhu, X. Wang, X. Liu, and X. Yang, "Integrated synthesis of poly(O-phenylenediamine)-derived carbon materials for high performance supercapacitors," Advanced Materials, vol. 24, no. 48, pp. 6524-6529, 2012. 

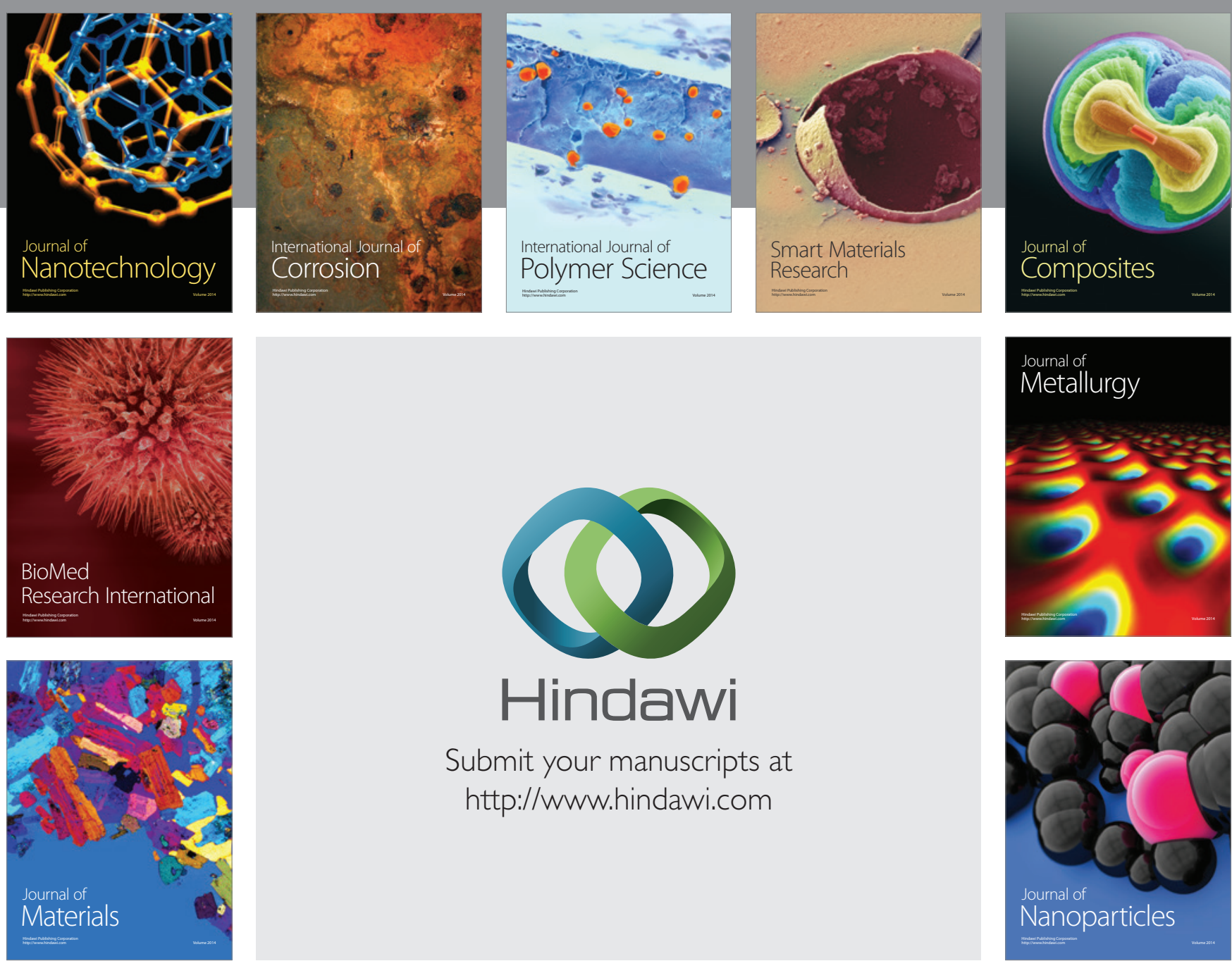

\section{Hindawi}

Submit your manuscripts at

http://www.hindawi.com

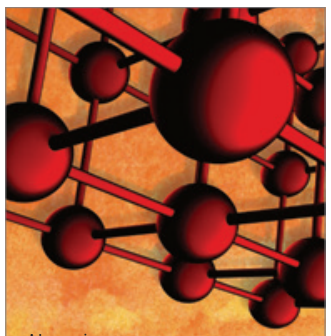

Materials Science and Engineering
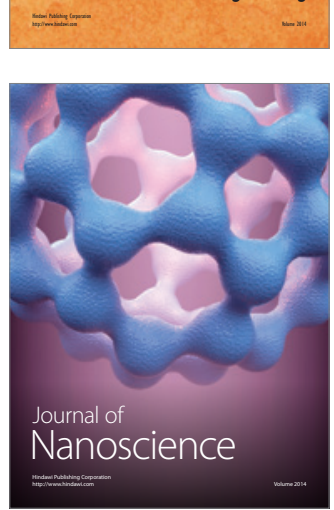
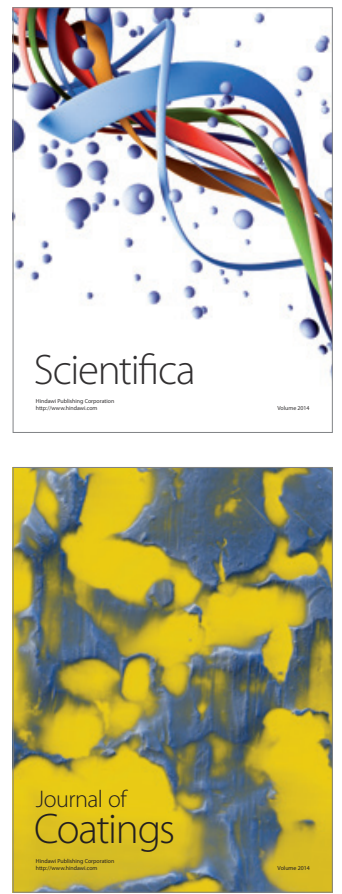
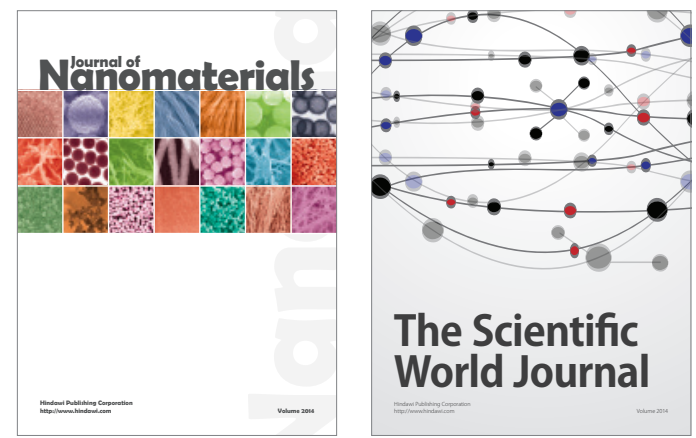

The Scientific World Journal
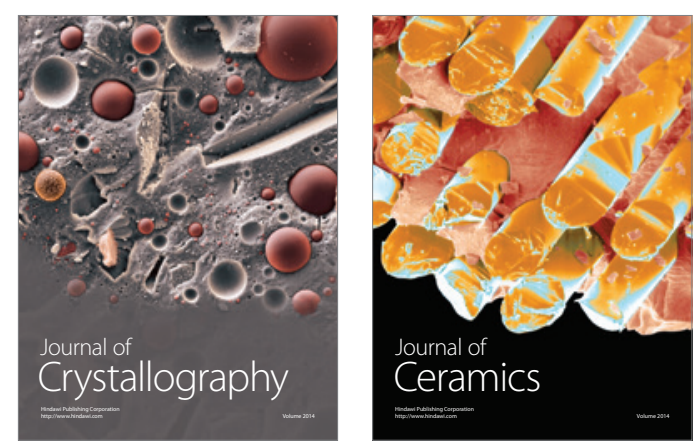
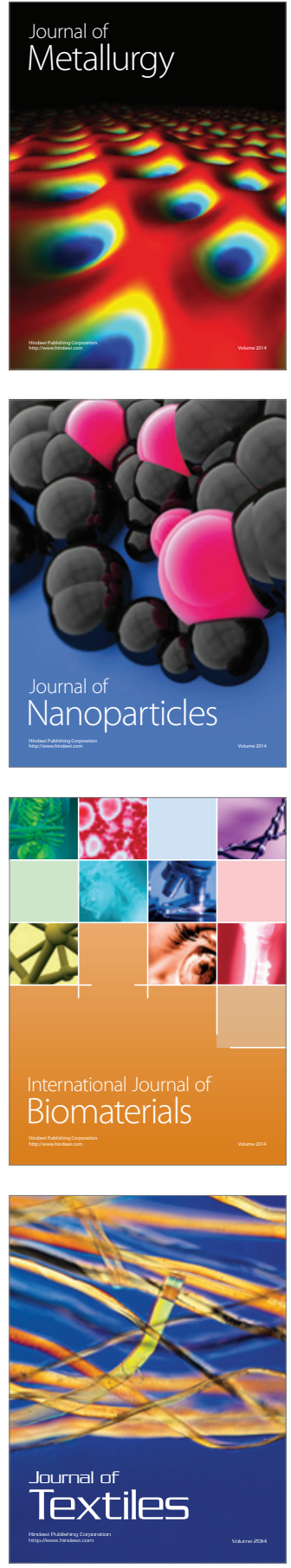